\title{
Sense of Coherence, Locus of Control, Self-Efficacy and Job Satisfaction
}

\section{S Rothmann}

Programme in Industrial and Personnel Psychology, Potchefstroom University for $C H E$

\begin{abstract}
Job satisfaction is a complex variable and is influenced by situational factors of the job environment as well as dispositional characteristics of the individual. Recently there has been renewed interest in the role of dispositional characteristics in predicting work-related outcomes. The aim of this study was to determine the possible relationship between the dispositional factors of sense of coherence, locus of control and self-efficacy on the one hand, and job satisfaction on the other. The study population included 624 employees of 7 organisations. Sense of coherence, locus of control and self-efficacy were found to be related constructs, but only sense of coherence and locus of control were significantly related to job satisfaction. Sense of coherence, locus of control and self-efficacy predicted 30 per cent of the variance in total job satisfaction.
\end{abstract}

JEL J 24

\section{INTRODUCTION}

Information on the job satisfaction of employees and correlates thereof is valuable for organisations. In a literature study, Roznowski and Hulin (1992) found that job dissatisfaction is related to absenteeism, trade union activities and psychological withdrawal. Steel and Rentsch (1995) found that job dissatisfaction correlated with absenteeism and employee turnover. According to Makin, Cooper and Cox (1996), employees' satisfaction with aspects of their jobs may influence their motivation. However, Iaffaldano and Muchinsky (1985) found an estimated correlation of only 0.17 between job satisfaction and job performance. In line with the opinion expressed by Bassett (1994), it is not assumed here that a more satisfied employee will be a more productive employee, nor is it assumed that job satisfaction is the result of high job performance.

Although global job satisfaction is not related to job performance, there are strong relationships between job satisfaction and organisational citizenship 
behaviour (Organ \& Konovsky, 1989). Organisational citizenship behaviour is behaviour that goes beyond what is formally required by the organisation. It is behaviour that is intended to assist the smooth running of the organisation (Makin et al., 1996). Individuals who are satisfied with their jobs are likely to be better ambassadors for the organisation and show more organisational commitment (Agho, Price \& Mueller, 1992).

Job satisfaction is an affective (emotional) reaction to a job, which stems from the incumbent's comparison of actual outcomes with the required outcomes (Cranny, Smith \& Stone, 1992). According to Weiss, Dawis, England and Lofquist (1967) employees seek to achieve and maintain correspondence with their environment. Correspondence with the environment can be described in terms of the individual fulfilling the requirements of the environment, and the environment fulfilling the requirements of the individual (Cook, Hepworth, Wall \& Warr, 1981). This means that employees would experience job satisfaction if they feel that their individual capacities, experience and values can be utilised in their work environment and that the work environment offers them oppornunities and rewards (Dawis, 1992; Roberts \& Roseanne, 1998).

Interactional explanations of job satisfaction are generally accepted, but the weight attached to dispositional and situational aspects vary. Dispositionists (e.g. House, Shane \& Herold, 1996) have contended that work attitudes and behaviour are determined by, or at least directly linked to, individual attributes. Situationists (e.g. Davis-Blake \& Pfeffer, 1989), on the other hand, have argued that the world of work, job characteristics, organisational situations and economic conditions affect people much more strongly than do individual differences. Arvey, Carter and Buerkley (1991) suggested that dispositional factors account for 10-30 per cent of the variance in job satisfaction, that 40-60 per cent of the variance is associated with situational factors, and that interactive elements account for 10-20 per cent. Since Staw, Bell and Clausen (1986) discovered a link between childhood personality and job satisfaction, there has been considerable interest in the relationship between individual dispositions and job satisfaction.

Dispositional variables can be described as personality characteristics, needs, attitudes, preferences and motives that result in a tendency to react to situations in a predetermined (predisposed) manner (House et al., 1996). In recent years, researchers have begun to explore the psychological processes that might underlie dispositional causes of job satisfaction. Weiss and Cropanzano (1996) suggested that affective temperament may influence the experience of emotionally significant events at work, which in turn influence job satisfaction. However, House et al. (1996) noted in their review of the dispositional literature that affective disposition is only one of many traits that can and should be 
studied. Judge, Locke, Durham and Kluger (1998) explained dispositional determinants of job satisfaction in terms of "core evaluations" (incorporating self-esteem, generalised self-efficacy, low neuroticism and locus of control), which can be described as fundamental evaluations that individuals make about themselves. Judge et al. (1998) found that individuals with a positive selfevaluation were more likely to assess their job satisfaction at higher levels than individuals with less positive self-evaluations.

In this research, the dispositional causes of job satisfaction are studied from a salutogenic paradigm (which focuses on the origins of health) (Antonovsky, 1987; Strümpfer, 1990) or fortigenic paradigm (which focuses on the origins of strengths) (Strümpfer, 1995). Strümpfer $(1990,1995)$ reviewed a number of constructs which have developed independently but which seem part of the fortigenic paradigm, including sense of coherence (Antonovsky, 1987), personality hardiness (Kobasa, 1982), potency (Ben-Sira, 1985) and learned resourcefulness (Rosenbaum, 1988). Constructs such as internal-external locus of control (Rotter, 1966) and self-efficacy (Bandura, 1989) can be regarded as fortigenesis-related. This study deals with the relationship between job satisfaction and three dispositional factors, namely sense of coherence, locus of control and self-efficacy.

The objectives of this research were to determine the relationship between psychological strengths (sense of coherence, locus of control and self-efficacy) and job satisfaction of employees and to determine whether these strengths could predict their job satisfaction. Research regarding employees' level of psychological strengths (sense of coherence, locus of control and self-efficacy) and the relationships of these with job satisfaction may provide useful information for the implementation of organisational socialisation programmes (such as recruitment, selection, induction and development programmes).

\section{THEORETICAL BACKGROUND}

\subsection{Sense of coherence}

Antonovsky $(1987,1991)$ developed the construct "sense of coherence". Sense of coherence can be described as a global orientation that expresses the extent to which one has a pervasive, enduring though dynamic feeling of confidence that one's internal and external environments are predictable and that there is a high probability that things will work out as well as can be reasonably expected. It thus influences an individual's perception of stimuli. 
The definition of sense of coherence includes three dimensions which represent the concept, namely comprehensibility, manageability and meaningfulness (Antonovsky, 1987).

Comprehensibility refers to the extent to which one perceives stimuli from the internal and external environment as information that is ordered, structured and consistent. The stimuli are perceived as comprehensible and make sense on a cognitive level.

Manageability refers to the extent to which individuals experience events in life as situations that are endurable or manageable and can even be seen as new challenges.

Meaningfulness refers to the extent to which one feels that life is making sense on an emotional and not just a cognitive level.

Antonovsky (1987) stated that the primary development of the dynamics of sense of coherence takes place in the first decade of one's adult life. Antonovsky (1987) also said that one's sense of coherence is tried continually, but individuals who developed a strong sense of coherence early in adulthood have the ability to use general resistance resources to restore equilibrium. Sense of coherence can thus be viewed as a stable dispositional orientation.

A strong sense of coherence is negatively related to measures of negative affectivity, such as anxiety and neuroticism (Carmel \& Bernstein, 1990; Flannery \& Flannery, 1990; Frenz, Carey \& Jorgenson, 1993) and work stress (Feldt, 1997). A strong sense of coherence is also related to competence and life satisfaction (Kalimo \& Vuori, 1990), general well-being (Feldt, 1997), and to emotional stability (Mlonzi \& Strümpfer, 1998). Strümpfer, Danana, Gouws and De Villiers (1998) found a moderate correlation $(r=0.47)$ between sense of coherence and job satisfaction.

Individuals with a strong sense of coherence should be able to make cognitive sense of the workplace, perceiving its stimulation as clear, ordered, structured, consistent and predictable information. They should experience their work as consisting of experiences that are bearable, with which they can cope, and as challenges that they can meet by availing themselves of personal resources or resources under the control of legitimate others. Lastly, they should be able to make emotional and motivational sense of work demands as welcome challenges, worthy of engaging in and investing their energies in. However, sense of coherence on its own, without the appropriate ability, skills, training and development, would be of no avail (Strümpfer, 1990). 


\subsection{Locus of control}

The construct of locus of control was developed by Rotter (1966) and is described as the extent to which individuals feel that they play a causative role in events in their lives. Rotter (1966) defined locus of control as a generalised expectancy of perceived internal or external control of reinforcement. Individuals may show an internal or an external locus of control. The former means that positive and/or negative outcomes are attributed to own actions and are consequently regarded as being under personal control. An external locus of control means that positive and/or negative outcomes are regarded as unrelated to own behaviour and are therefore beyond personal control. Schepers (1995) found that the construct locus of control consists of three independent factors, namely internal control, autonomy and external control.

Individuals with an internal locus of control will probably feel that they can manage situations in work context, because these are seen as being within their personal control (Judge et al., 1998). Compared to individuals with an extemal locus of control, they will be less inclined to cope with frustrations in organisations by withdrawing or by reacting aggressively (Rahim \& Psenicka, 1996; Spector, 1982). They are also more successful in personal relationships than individuals with an external locus of control (Mayer \& Sutton, 1996). Individuals with an external locus of control look at others for direction, while those with an internal locus of control depend on themselves for direction (Spector, 1982).

Spector (1986) found that high levels of perceived control was associated with high levels of job satisfaction, commitment and involvement, and low levels of stress, absenteeism and turnover. The studies of Garson and Stanwyck (1997), Jain, McLaughlin, Lall and Johnson (1996) and Judge et al. (1998) confirmed a relationship between an internal locus of control and job satisfaction. An individual with an internal locus of control is expected to be more satisfied with his or her job because of his or her perceived ability to control situations.

\subsection{Self-efficacy}

The concept of self-efficacy, which was developed by Bandura $(1982,1989)$, is described as the judgements of individuals regarding their skills in carrying out the required behaviour performing particular types of actions. Wood and Bandura (1989: 408) defined self-efficacy as "... beliefs in one's capabilities to mobilise the motivation, cognitive resources, and courses of action needed to meet given organisational demands." Self-efficacy is a belief in the probability that one can successfully execute some future action or task to achieve some 
result. In work context, self-efficacious employees believe that they are likely to be successful at most or all of their job duties and responsibilities (Gardner \& Pierce, 1998).

According to Gardner and Pierce (1998) and Judge et al. (1998) self-efficacy can be viewed from both a specific and a general angle. Task-specific selfefficacy is a state-based expectation or judgement about the likelihood of successful task performance measured immediately before any effort is expended on the task. It is a powerful motivator of behaviour because efficacy expectations at a given point in time determine the initial decision to perform a task, the effort expended and the level of persistence that emerges in the face of adversity. Self-efficacy can also be viewed as a general, stable cognition (trait) that individuals hold and carry with them, that reflects the expectation that they possess the ability to perform tasks successfully in a variety of achievement situations (Eden \& Zuk, 1995).

According to Gardner and Pierce (1998), self-efficacy gradually emerges through the experiences that the individual accumulates. The cognitive appraisal and integration of the data stemming from these experiences ultimately determine an individual's self-efficacy. Frequent situation-specific experiences of personal success across time and situations give rise to generalised selfefficacy. Factors that are likely to lead to high generalised self-efficacy include repeated success at a specific task, the accumulation of successful experiences across a wide variety of tasks and feedback from the work environment that the individual is successful (Gardner \& Pierce, 1998). Sherer et al. (1982) found that individuals who have developed a generalised view of themselves as efficacious individuals also hold positive images of themselves. Stanley and Murphy (1997) criticised generalised self-efficacy measures as measuring nothing but self-esteem. According to Judge et al. (1998) it could be expected that generalised self-efficacy would load on the same factor as self-esteem (because self-efficacy and self-worth are the core components of self-esteem).

The major consequence of strong specific self-efficacy perceptions is enhanced task performance (Sadri \& Robertson, 1993). General self-efficacy has been hypothesised to be a strong determinant of specific self-efficacy (Eden, 1988). Although self-efficacy theory is somewhat silent on possible effects of selfefficacy on employee attitudes, it seems plausible that the higher one's level of self-efficacy in some task, the higher one's positive affect associated with it (Lee \& Bobko, 1994; Schwoerer \& May, 1996). According to Bandura (1989) employees with a low level of self-efficacy doubt their capabilities, shy away from difficult tasks and have low aspirations and weak commitment to the goals they choose to pursue. Wood and Bandura (1989) suggested that inefficacious thoughts could cause distress and depression, which could then lead to reduced 
levels of satisfaction. Judge et al. (1998) concluded that self-efficacy indirectly influences job satisfaction in the sense that perceptions of work attributes, which influence job satisfaction, are affected.

\subsection{The relationship between sense of coherence, locus of control and self- efficacy}

The literature provides considerable amounts of research linking self-efficacy and locus of control. Sherer et al. (1982) claimed that attributional style is important for general self-efficacy. Individuals who bave an internal locus of control will attribute past success to themselves, and this tendency will boost their general self-efficacy. Shelton (1990) stated that past experiences with success or failure affect an individual's general self-efficacy depending on whether he or she attributes the success or failure to the self.

According to Lefcourt (1982) and Rotter (1966) individuals with an external locus of control tend to doubt their personal efficacy. Self-efficacy pertains to confidence with respect to actions or behaviour, whereas locus is more concerned with confidence in being able to control outcomes (Judge et al., 1998). Both self-efficacy and locus of control are cognitive constructs and are about control (Rotter, 1966). Breed (1997), who found a correlation of 0.37 between locus of control and generalised self-efficacy, stated that both constructs are concerned with the individual's experience of the self in control of his or her own world of experience and available resources.

Kalimo and Vuori (1990) stated that the sense of coherence concept involves some of the issues that can be found in locus of control theory. Sense of coherence refers to an internalised sense of control, which also guides orientation towards coming events. Sense of coherence helps individuals understand the various facets of control and their consequences through individuals' experience of the environment. It is in this regard that the sense of coherence concept is similar to the concept of locus of control because both lead to anticipatory health-promoting orientations (Seeman \& Seeman, 1983). According to Antonovsky (1987), differences exist in the conceptual definitions of sense of coherence and locus of control. Sense of coherence also views resources under the control of others as valuable, whereas locus of control views such resources as an external orientation and a failure to take control of their own destiny. Similarly, correlation coefficients between 0.38 and 0.44 have been found between sense of coherence and locus of control (Antonovsky, 1987).

The relationship between self-efficacy and sense of coherence is interesting, because self-efficacy is not primarily conceptualised in the fortigenic paradigm. Self-efficacy, like sense of coherence, is concerned with the individual's 
experience of forcefulness in his or her own world (Breed, 1997). According to Antonovsky (1987) the components of sense of coherence show similarities to the self-efficacy construct. Breed (1997) found a correlation of 0.53 between generalised self-efficacy and sense of coherence.

\section{RESEARCH METHOD}

\subsection{Research design}

A survey design was used to reach the research objectives. The specific design is the cross-sectional design, whereby information is collected from a sample or population at one time (Shaughnessy \& Zechmeister). This design can be used also to assess interrelationships among variables within a population. According to Shaughnessy and Zechmeister (1997) this design is ideally suited to the descriptive and predictive functions associated with correlational research. Correlational research is the method of choice when the goal of the research is prediction. However, there are serious limitations to using the results of this type of research to infer causal relationships.

\subsection{Study population}

The study population $(N=624)$ included samples of the following organisations in South Africa:

- The total population of representatives $(n=55)$ of a fertiliser marketing company in South Africa. Approximately 98 per cent of the population consisted of males. The age of the group varied between 20 and 60 years.

- A stratified random sample $(n=98)$ of the employees of a financial institution in South Africa $(N=500)$. Approximately 51 per cent of the participants were males, 77 per cent below the age of 40 and 15 per cent part of management.

- A non-probability sample $(n=81)$ of managers in the dairy industry in South Africa $(N=121)$. A total of 89 per cent of the participants were males. The age of the participants varied between 20 and 60 years.

- The total population of senior police officers $(n=101)$ in the North West Province in South Africa. All the participants were males aged between 26 and 55 years.

- The total population of supervisory and management personnel $(n=129)$ of a cigarette manufacturing company in South Africa. A total of 97.7 per cent of the participants were males. The age of the participants varied between 24 and 61 years. 
- A stratified random sample $(n=100)$ of health services workers in a state hospital in the North West Province in South Africa $(N=300)$. Approximately 86 per cent of the participants were females, 74 per cent below the age of 40 and 32 per cent part of management.

- A non-probability sample $(n=60)$ of employees of an estate agency in South Africa $(N=130)$. Approximately 63 per cent of the participants were females, 60 per cent below the age of 40 and 20 per cent part of management.

\subsection{Measuring instruments}

The Minnesota Satisfaction Questionnaire (MSQ) (Weiss et al., 1967) was used to measure employees' job satisfaction. Test-retest reliabilities of 0.70 and 0.80 were found over a span of a week and a year respectively (Cook et al., 1981). In this study a Cronbach alpha coefficient of 0.96 was found for total job satisfaction (see Table 1). The mean inter-item correlation is 0.22 , which is acceptable for broad higher order constructs (Clark \& Watson, 1995).

The Orientation to Life Questionnaire (OLQ) (Antonovsky, 1987, 1993) was used to measure participants' sense of coherence. Antonovsky $(1987,1993)$ reported Cronbach alpha coefficients ranging between 0.84 and 0.93 for the OLQ. Kalimo and Vuori (1990) found a test-retest reliability of 0.93 for the OLQ, while Antonovsky (1993) reported test-retest reliability coefficients varying between 0.41 and 0.97 . Regarding construct validity, it was found that there is an inverted relationship between the OLQ and stress experienced. The OLQ correlates negatively with the "State-Trait Anxiety Inventory-Trait" and the "Beck Depression Inventory" (Frenz, Carey \& Jorgensen, 1993).

The Locus of Control Questionnaire (LOC) (Schepers, 1995) was used to measure locus of control. The LOC measures three factors, namely internal control, external control and autonomy. External Control measures the extent to which the respondent attributes performance to forces outside his or her control (luck, fate, circumstances or influential people). Internal Control measures whether the respondent attributes performance to causes within his or her control (abilities, behaviour or personal characteristics). Autonomy measures whether the respondent's believes in his or her abilities, acts independently with self-confidence, and decides on and takes action to solve problems. An item analysis of the three scales revealed reliability scores higher that 0.80 . Research by Schepers (1995) established the Cronbach alpha coefficients of the three scales of the LOC at 0.83 (Internal Control), 0.84 (External Control) and 0.87 (Autonomy). Schepers (1995) found that external and internal control are not bipolar opposites, but independent constructs. In terms of criterion validity, it 
has been found that the LOC correlates with a composite criterion of job success $(r=0.62)$ (Bothma \& Schepers, 1997).

The General Self-Efficacy Questionnaire (GSE) (Tipton \& Worthington, 1984) was used to determine how the individual judges his or her own abilities and regulates the experience of personal efficacy with regard to incidents in his or her life. Tipton and Worthington reported that they based their GSE scale on the concept of faith, especially faith in oneself. Marais (1997) and Stanley and Murphy (1997) obtained Cronbach alpha coefficients of 0.71 and 0.83 respectively for the GSE scale.

\subsection{Statistical analysis}

The statistical analysis was carried out by means of the SAS-program (SAS Institute, 1996). Because a non-probability sample was used in this research, effect sizes (rather than inferential statistics) were used. Cronbach alpha coefficients were calculated to indicate the internal consistency of the measuring instruments. Pearson product-moment correlation coefficients were used to specify the relationships between the variables. A cut-off point of 0.30 (medium effect, Cohen, 1988) was set for the practical significance of correlation coefficients. Analysis of variance was used to determine the differences between the job satisfaction, sense of coherence, locus of control and self-efficacy of employees of different organisations. The following formula was used to compute the effect sizes ( $d$ in Table 2) of these differences (Steyn, 1999):

$$
\frac{M_{A}-M_{B}}{\sqrt{M S E}}
$$

with

$M_{\mathrm{A}}=$ Mean of the construct in one organisation

$M_{\mathrm{B}}=$ Mean of the construct in another organisation

$M S E=$ Mean square error.

A cut-off point of 0.5 (medium effect, Cohen, 1988) was set for the practical significance of differences. A stepwise multiple regression analysis was conducted to determine the proportion of variance in the dependent variable (job satisfaction) that is predicted by the independent variables (sense of coherence, locus of control and self-efficacy). The effect size (which indicates practical significance) in the case of multiple regression is given by the following formula (Steyn, 1999):

$$
f^{2}=R^{2} /\left(1-R^{2}\right)
$$


A cut-off point of 0.35 (large effect, Steyn, 1999) was set for the practical significance of $f^{2}$.

\section{RESULTS}

The descriptive statistics and the internal consistency of the measuring instruments for the total population are reported in Table 1.

Table 1 Descriptive statistics and alpha coefficients of the measuring instruments

\begin{tabular}{|l|l|l|l|l|l|}
\hline \multicolumn{1}{|c|}{ Item } & \multicolumn{1}{c|}{$\boldsymbol{M}$} & \multicolumn{1}{c|}{ SD } & \multicolumn{1}{c|}{ Skewness } & Kurtosis & $\alpha$ \\
\hline Job Satisfaction $(N=624)$ & 490.60 & 76.56 & 0.81 & 0.99 & 0.96 \\
\hline Total & 140.41 & 21.89 & -0.22 & 0.04 & 0.89 \\
\hline Sense of Coherence $(N=521)$ & & 0.00 & -0.31 & 0.74 \\
\hline OLQ & 8.96 & -0.25 & -0.18 & 0.75 \\
\hline Comprehensibility & 48.77 & 8.42 & -0.86 & 0.58 & 0.82 \\
\hline Manageability & 48.13 & & & \\
\hline Meaningfulness & 43.50 & 7.98 & -1.08 & 4.94 & 0.86 \\
\hline Locus of Control $(N=534)$ & & 14.87 & 0.07 & -0.24 & 0.80 \\
\hline LOC: Internal & 146.81 & 20.52 & -0.56 & 1.74 & 0.81 \\
\hline LOC: External & 84.54 & 15.92 & & & \\
\hline LOC: Autonomy & 136.65 & & 1.36 & 4.10 & 0.94 \\
\hline Self-Efficacy $(N=282)$ & 74.69 & 18.34 & & \\
\hline GSE & & & & \\
\hline
\end{tabular}

Table 1 shows that the scores on the measuring instruments of job satisfaction and psychological strengths are relatively normally distributed with the LOC: Internal scores somewhat negatively skew while the GSE scores show a positive skewness and kurtosis. The Cronbach alpha coefficients of the MSQ, the OLQ, the LOC and the GSE confirm their internal consistency when compared with the norm of 0.80 set by Nunnally and Bernstein (1994).

Table 2 shows the differences between the means of the measuring instruments in the different organisations included in this study. 


\begin{tabular}{|c|c|c|c|c|c|c|c|c|c|c|c|c|}
\hline \multirow[t]{2}{*}{ Item } & \multicolumn{2}{|c|}{ MSQ } & \multicolumn{2}{|c|}{ OLQ } & \multicolumn{2}{|c|}{$\begin{array}{c}\text { LOC: } \\
\text { External }\end{array}$} & \multicolumn{2}{|c|}{$\begin{array}{l}\text { LOC: } \\
\text { Internal }\end{array}$} & \multicolumn{2}{|c|}{$\begin{array}{c}\text { LOC: } \\
\text { Autonomy }\end{array}$} & \multicolumn{2}{|c|}{ GSE } \\
\hline & $M$ & $S D$ & $M$ & $S D$ & $M$ & $S D$ & $M$ & $S D$ & $M$ & $S D$ & $M$ & $S D$ \\
\hline $\begin{array}{l}\text { Fertiliser } \\
\text { Marketing } \\
\text { Company }\end{array}$ & $\begin{array}{r}503.64 \\
b^{\prime}\end{array}$ & 63.65 & 139.71 & 20.69 & $\begin{array}{r}79.58 \\
\mathrm{f}\end{array}$ & 20.49 & 150.84 & 11.39 & $\begin{array}{r}142.40 \\
h\end{array}$ & 13.98 & 73.13 & 20.75 \\
\hline $\begin{array}{l}\text { Financial } \\
\text { Institution }\end{array}$ & 483.39 & 89.12 & 139.96 & 23.31 & 83.41 & 22.34 & 145.04 & 18.53 & 135.07 & 19.63 & 75.15 & 17.34 \\
\hline $\begin{array}{l}\text { Dairy } \\
\text { Industry }\end{array}$ & $\begin{array}{r}506.84 \\
b^{1}\end{array}$ & 74.34 & $\begin{array}{r}143.11 \\
d\end{array}$ & 21.43 & - & - & - & - & - & - & - & - \\
\hline $\begin{array}{l}\text { Police } \\
\text { Service }\end{array}$ & 483.67 & 65.28 & - & - & 85.79 & 19.16 & 148.91 & 13.62 & $\begin{array}{r}141.73 \\
h\end{array}$ & 13.10 & - & - \\
\hline $\begin{array}{l}\text { Cigarette } \\
\text { Manu- } \\
\text { facturing } \\
\text { Company }\end{array}$ & $\begin{array}{r}511.87 \\
b^{2}\end{array}$ & 73.23 & $\begin{array}{r}147.31 \\
d\end{array}$ & 18.41 & $\begin{array}{r}80.19 \\
f\end{array}$ & 19.36 & 145.75 & 13.03 & $\begin{array}{r}142.19 \\
h\end{array}$ & 12.80 & 75.00 & 18.09 \\
\hline $\begin{array}{l}\text { Health } \\
\text { Services } \\
\text { Institution }\end{array}$ & $\begin{array}{r}452.95 \\
\mathrm{a}\end{array}$ & 76.35 & $\begin{array}{r}131.20 \\
\mathrm{c}\end{array}$ & 20.62 & $\begin{array}{r}93.03 \\
\mathrm{e}\end{array}$ & 16.79 & 145.86 & 16.32 & $\begin{array}{r}127.08 \\
\mathrm{~g}\end{array}$ & 14.33 & - & - \\
\hline $\begin{array}{l}\text { Estate } \\
\text { Agency }\end{array}$ & $\begin{array}{r}497.18 \\
b^{1}\end{array}$ & 69.81 & 136.68 & 24.97 & 83.94 & 24.17 & 146.19 & 13.49 & $\begin{array}{r}128.34 \\
\mathrm{~g}\end{array}$ & 12.31 & - & - \\
\hline
\end{tabular}


a Practically significant difference from the organisations where $b^{\prime}$ (medium effect, $d \geq 0.5$ ) and $b^{2}$ (large effect, $d \geq 0.8$ ) are indicated

c Practically significant difference (medium effect, $d \geq 0.5$ ) from organisations where $d$ is indicated

e Practically significant difference (medium effect, $d \geq 0.5$ ) from organisations where $f$ is indicated

g Practically significant difference (large effect, $d \geq 0.8$ ) from organisations where $h$ is indicated

Table 2 shows practically significant differences between the job satisfaction of participants of the health services institution and all the other organisations, except for the police service. These participants also obtained practically significant lower scores on sense of coherence than those of the dairy industry and the cigarette manufacturing company. Regarding external locus of control, participants of the health institution obtained practically significant higher scores than those of the fertiliser marketing company and the cigarette manufacturing company. Participants of the fertiliser marketing company, the police service and the cigarette manufacturing company obtained practically significant higher scores on autonomy, compared with those of the health services institution and the estate agency.

The Pearson product-moment correlation coefficients between the different constructs are given in Table 3.

Table 3 Pearson product-moment correlation coefficients between total job satisfaction and psychological strengths

\begin{tabular}{|l|c|c|c|c|c|}
\hline \multicolumn{1}{|c|}{ Item } & $\begin{array}{c}\text { OLQ: } \\
\text { Total }\end{array}$ & $\begin{array}{c}\text { LOC: } \\
\text { External }\end{array}$ & $\begin{array}{c}\text { LOC: } \\
\text { Internal }\end{array}$ & $\begin{array}{c}\text { LOC: } \\
\text { Autonomy }\end{array}$ & GSE \\
\hline $\begin{array}{l}\text { Total Job } \\
\text { Satisfaction }\end{array}$ & $0.50^{* *}$ & $0.43^{*}$ & $0.30^{*}$ & $0.37^{*}$ & -0.10 \\
\hline $\begin{array}{l}\text { OLQ: } \\
\text { Total }\end{array}$ & - & $-0.56^{*}$ & $0.32^{*}$ & $0.47^{*}$ & $-0.41^{*}$ \\
\hline $\begin{array}{l}\text { LOC: } \\
\text { External }\end{array}$ & - & - & -0.17 & $-0.30^{*}$ & 0.25 \\
\hline $\begin{array}{l}\text { LOC: } \\
\text { Internal }\end{array}$ & - & - & - & $0.65^{* *}$ & -0.25 \\
\hline $\begin{array}{l}\text { LOC: } \\
\text { Autonomy }\end{array}$ & - & - & - & & $-0.39^{*}$ \\
\hline
\end{tabular}

* Correlation is practically significant $r>0.30$ (medium effect)

** Correlation is practically significant $r>0.50$ (large effect) 
Table 3 shows practically significant correlation coefficients of large effect ( $r \geq$ 0.50) regarding the following items: Sense of coherence and total job satisfaction, sense of coherence and external locus of control (negative correlation) as well as internal locus of control and autonomy. Practically significant relationships of medium effect $(r \geq 0.30)$ exist between sense of coherence and self-efficacy, sense of coherence and autonomy, self-efficacy and internal locus of control, as well as self-efficacy and autonomy. The negative correlation coefficients between generalised self-efficacy and the other constructs could be expected because a low score on the GSE is indicative of a positive adaptation. The results in Table 3 indicate that all the psychological strengths had some significant correlation with job satisfaction, except selfefficacy, which showed no practically significant correlation with job satisfaction.

Next, the correction for attenuation was computed to estimate how high the correlation between job satisfaction and the psychological strengths would be if the variables were made perfectly reliable. The correction for attenuation is computed by using the following formula:

$$
\hat{r}_{x y}=\frac{r_{x y}}{\sqrt{r_{x y}}}
$$

where

$r_{x y}=$ the correlation between job satisfaction and the specific construct, and $r_{x}$ and $r_{y}=$ the reliabilities of the measures of job satisfaction and the specific construct.

Table 4 shows the corrected correlation coefficients between job satisfaction and psychological strengths.

Table 4 Corrected correlation coefficients between total job satisfaction and psychological strengths

\begin{tabular}{|l|l|l|l|l|l|}
\hline \multicolumn{1}{|c|}{ Item } & $\begin{array}{c}\text { OLQ: } \\
\text { Total }\end{array}$ & $\begin{array}{c}\text { LOC: } \\
\text { External }\end{array}$ & $\begin{array}{c}\text { LOC: } \\
\text { Internal }\end{array}$ & $\begin{array}{c}\text { LOC: } \\
\text { Autonomy }\end{array}$ & \multicolumn{1}{c|}{ GSE } \\
\hline $\begin{array}{l}\text { Total Job } \\
\text { Satisfaction }\end{array}$ & $0.54^{* *}$ & $-0.49^{*}$ & $0.33^{*}$ & $0.42^{*}$ & -0.11 \\
\hline
\end{tabular}

* Correlation is practically significant $r>0.30$ (medium effect)

** Correlation is practically significant $r>0.50$ (large effect) 
Table 5 shows the homogeneity of the correlation coefficients between psychological strengths (including only sense of coherence and locus of control) and job satisfaction in the different organisations. The method of Fisher, who devised a transformation from $r$ to a quantity $z$ was used to test the hypothesis that several $r s$ are estimates of the same $\rho$ (Snedecor \& Cochran, 1980). First each $r$ was converted to $z$ and the term $(n-3)$ was recorded for each $z$. The test of significance was based on the following formula:

$$
\chi^{2}=\frac{\Sigma(n-3) z^{2}-[\Sigma(n-3) z]^{2}}{\Sigma(n-3)}
$$

The obtained value was compared with the $\chi^{2}$ table to determine whether the $\mathrm{p}$ value was significant. The cut-off point for the statistical significance of $p$ was set at 0.05 .

Table 5 Homogeneity of the correlation coefficients between psychological strengths and total job satisfaction in different organisations

\begin{tabular}{|c|c|c|c|c|c|c|}
\hline Study & $n$ & $w=\mathbf{n}-\mathbf{3}$ & $\boldsymbol{r}$ & $z$ & $w^{\star} z$ & $w^{\star} z^{\wedge} 2$ \\
\hline \multicolumn{7}{|c|}{ MSQ and OLQ: $\chi^{2}=9.79 p=0.08$ Pooled $z=0.49$ Pooled $r=0.45$} \\
\hline $\begin{array}{l}\text { Fertiliser Marketing } \\
\text { Company }\end{array}$ & 55 & 52 & 0.26 & 0.27 & 13.84 & 3.68 \\
\hline Financial Institution & 98 & 95 & $0.56^{* *}$ & 0.63 & 60.12 & 38.05 \\
\hline Dairy Industry & 81 & 78 & $0.55^{* *}$ & 0.62 & 48.23 & 29.83 \\
\hline $\begin{array}{l}\text { Cigarette Manufacturing } \\
\text { Company }\end{array}$ & 129 & 126 & $0.38^{*}$ & 0.40 & 50.41 & 20.17 \\
\hline Health Services Institution & 100 & 97 & $0.36^{*}$ & 0.38 & 36.56 & 13.78 \\
\hline Estate Agency & 60 & 57 & $0.58^{* * *}$ & 0.66 & 37.76 & 25.01 \\
\hline \multicolumn{7}{|c|}{$\begin{array}{l}\text { MSQ and LOC - Extemal: } \chi^{2}=7.15 p=0.21 \text { Pooled } z=-0.42 \text { Pooled } r= \\
0.40\end{array}$} \\
\hline $\begin{array}{l}\text { Fertiliser Marketing } \\
\text { Company }\end{array}$ & 55 & 52 & $-0.43^{*}$ & -0.46 & -23.91 & 11.00 \\
\hline Financial Institution & 98 & 95 & $-0.46^{*}$ & -0.50 & -47.24 & 23.50 \\
\hline Police Services & 101 & 98 & $-0.44^{*}$ & -0.47 & -46.28 & 21.85 \\
\hline
\end{tabular}


Table 5 continued

\begin{tabular}{|c|c|c|c|c|c|c|}
\hline Study & $n$ & $w=\mathbf{n}-\mathbf{3}$ & $r$ & $z$ & $w * z$ & $w^{\star} z^{\wedge} 2$ \\
\hline $\begin{array}{l}\text { Cigarette Manufacturing } \\
\text { Company }\end{array}$ & 129 & 126 & $-0.32^{*}$ & -0.33 & -41.79 & 13.86 \\
\hline Health Services Institution & 100 & 97 & -0.26 & -0.27 & -25.81 & 6.87 \\
\hline Estate Agency & 60 & 57 & $0.57^{-*}$ & -0.65 & -36.91 & 23.90 \\
\hline \multicolumn{7}{|c|}{ MSQ and LOC - Internal: $\chi^{2}=9.55 \mathrm{p}=0.09$ Pooled $z=0.32$ Pooled $r=0.31$} \\
\hline $\begin{array}{l}\text { Fertiliser Marketing } \\
\text { Company }\end{array}$ & 55 & 52 & 0.26 & 0.27 & 13.84 & 3.68 \\
\hline Financial Institution & 98 & 95 & $0.42^{*}$ & 0.45 & 42.53 & 19.04 \\
\hline Police Services & 101 & 98 & 0.14 & 0.14 & 13.81 & 1.95 \\
\hline $\begin{array}{l}\text { Cigarette Manufacturing } \\
\text { Company }\end{array}$ & 129 & 126 & $0.31^{*}$ & 0.32 & 40.39 & 12.95 \\
\hline Health Services Institution & 100 & 97 & 0.24 & 0.24 & 23.74 & 5.81 \\
\hline Estate Agency & 60 & 57 & $0.53^{* *}$ & 0.59 & 33.64 & 19.85 \\
\hline \multicolumn{7}{|c|}{$\begin{array}{l}\text { MSQ and LOC - Autonomy: } \chi^{2}=8.12 p=0.15 \text { Pooled } z=0.33 \text { Pooled } r= \\
0.31\end{array}$} \\
\hline $\begin{array}{l}\text { Fertiliser Marketing } \\
\text { Company }\end{array}$ & 55 & 52 & $0.45^{*}$ & 0.49 & 25.20 & 12.22 \\
\hline Financial Institution & 98 & 95 & $0.49^{\circ}$ & 0.54 & 50.93 & 27.30 \\
\hline Police Services & 101 & 98 & 0.20 & 0.20 & 19.87 & 4.03 \\
\hline $\begin{array}{l}\text { Cigarette Manufacturing } \\
\text { Company }\end{array}$ & 129 & 126 & 0.25 & 0.26 & 32.18 & 8.22 \\
\hline Health Services Institution & 100 & 97 & 0.25 & 0.26 & 24.78 & 6.33 \\
\hline Estate Agency & 60 & 57 & $0.30^{*}$ & 0.31 & 17.64 & 5.46 \\
\hline
\end{tabular}

* Correlation is practically significant $r>0.30$ (medium effect)

** Correlation is practically significant $r>0.50$ (large effect)

Table 5 shows that different correlation coefficients were obtained between job satisfaction on the one hand and sense of coherence and locus of control on the other hand. However, the differences between the correlation coefficients are not statistically significant. 
Next, a regression analysis of the various psychological strengths (as independent variables) and job satisfaction (as measured by the MSQ) as dependent variable was conducted (see Table 6).

Table 6 Regression analysis of OLQ, LOC, GSE and MSQ

ANALYSIS OF VARIANCE

\begin{tabular}{|c|c|c|c|c|c|c|}
\hline$R=0.55$ & $\begin{array}{c}\text { Source of } \\
\text { variance }\end{array}$ & \multicolumn{2}{|c|}{$\begin{array}{l}\text { Degrees of } \\
\text { freedom }\end{array}$} & \multicolumn{2}{|c|}{$\begin{array}{l}\text { Sum of } \\
\text { squares }\end{array}$} & Mean square \\
\hline \multirow[t]{3}{*}{$R^{2}=0.30$} & Regression & \multicolumn{2}{|r|}{5} & \multicolumn{2}{|c|}{507720.15} & 101544.03 \\
\hline & Residual & \multicolumn{2}{|c|}{275} & \multicolumn{2}{|c|}{1201643.91} & 4369.61 \\
\hline & $F=23.24$ & \multicolumn{2}{|c|}{$f^{2}=0.43$} & & & \\
\hline \multicolumn{7}{|c|}{ VARIABLES IN THE EQUATION } \\
\hline $\begin{array}{c}\text { Independent } \\
\text { variables }\end{array}$ & \begin{tabular}{|l|}
$\boldsymbol{B}$ \\
\end{tabular} & $S E$ of $B$ & Par & tial $\mathbf{R}^{2}$ & $\boldsymbol{F}$ & $p$ \\
\hline Constant & 167.27 & 65.27 & & - & 6.57 & 0.01 \\
\hline OLQ (SOC) & 1.03 & 0.26 & & 0.20 & 16.34 & 0.00 \\
\hline LOC: External & -0.78 & 0.23 & & 0.03 & 11.80 & 0.00 \\
\hline LOC: Internal & 0.64 & 0.39 & & 0.04 & 2.60 & 0.11 \\
\hline LOC: Autonomy & 0.75 & 0.42 & & 0.01 & 3.20 & 0.07 \\
\hline GSE & 0.68 & 0.24 & & 0.02 & 7.91 & 0.00 \\
\hline
\end{tabular}

Table 7 demonstrates that sense of coherence, locus of control (external control, internal control and autonomy) and self-efficacy predict a total of 30 per cent of the variance of total job satisfaction (as measured by the MSQ). The multiple correlation of 0.55 is practically significant (large effect) $\left(f^{2}=0.43\right.$ ). These findings indicate that sense of coherence, locus of control and self-efficacy predict approximately 30 per cent of the variance in job satisfaction.

\section{DISCUSSION}

The results of the empirical study show that health services employees (who work for the provincial government) are significantly less satisfied with their jobs compared with employees in the other organisations. High demands, money shortages and organisational transformation affect the health services in the province, which may be related to employees' lower job satisfaction. Furthermore, the results show that these employees also achieved practically 
significant lower scores on sense of coherence and autonomy and higher scores on external locus of control.

A practically significant correlation was found between sense of coherence and total job satisfaction, which confirms previous research findings (Strimpfer et al., 1998). Practically significant correlation coefficients were also found between job satisfaction on the one hand and external locus of control, internal locus of control and autonomy on the other hand.

Locus of control (including internal locus of control, external locus of control and autonomy) correlated significantly with total job satisfaction. An employee who attributes performance to causes within his or her control, believes in his or her ability, acts independently with self-confidence and decides on and takes action to solve problems will experience more job satisfaction than those who do not. This finding confirms findings of other researchers (e.g. Garson \& Stanwyck, 1997; Jain et al., 1996; Spector, 1986) that an internal locus of control is related to job satisfaction. Employees who perceive that they have the ability to control situations are more satisfied with their jobs.

No practically significant correlation was found between self-efficacy and job satisfaction. The absence of significant correlation coefficients is contradictory to the findings of Judge et al. (1998) that self-efficacy is a better predictor of job satisfaction than locus of control. The expectation that higher generalised selfefficacy would be related to higher positive affect towards one's job did not realise in this study. However, Gardner and Pierce (1998) noted that generalised self-efficacy has not had a strong track record in laboratory experiments and other well-controlled studies. This may be the reason for the low correlation between job satisfaction and generalised self-efficacy. Other reasons may be that the measuring instrument is lacking validity. On the other hand, it may also be useful to relate job satisfaction to task-specific self-efficacy rather than generalised self-efficacy (Bandura, 1989).

The correlation coefficients between job satisfaction on the one hand and sense of coherence, locus of control and generalised self-efficacy on the other, show the same tendencies in different organisations. However, in the case of the fertiliser marketing company, a stronger relationship was found between job satisfaction and autonomy in comparison with other organisations, while job satisfaction was not so strongly related to sense of coherence. This finding may be attributed to the nature of the job of the representative, which requires that he or she should work independently and with self-discipline. In most organisations an external locus of control was significantly negatively related to job satisfaction. 
Sense of coherence is negatively related to an external locus of control, and positively related to an internal locus of control, autonomy and generalised selfefficacy. Breed (1997) also found significantly positive relationships between self-efficacy and sense of coherence. (Note that a low score on the GSE indicates a higher generalised self-efficacy, which explains the negative correlation between sense of coherence and generalised self-efficacy.) Employees who experience stimuli from the environment as comprehensible, manageable and meaningful will therefore attribute performance to causes within his or her control (rather than forces outside their control), believe in their abilities, act independently with self-confidence and decide and take action to solve problems and show higher generalised self-efficacy.

It was found that an internal locus of control is significantly related to autonomy $(r=0.65)$, which supports the findings of Schepers (1995). An internal locus of control is also negatively related to an external locus of control $(r=-0.30)$, which suggests that the two scales are somewhat related. The results indicate that an internal locus of control and generalised self-efficacy are significantly related. Individuals who believe that they can control their behavioural outcomes could come up with the necessary resources and motivation to cope effectively with challenges and/or tasks at hand. Generalised self-efficacy and autonomy are also significantly related. The findings pertaining to self-efficacy and locus of control in this study are higher than those of Breed (1997).

The correlation coefficients between sense of coherence, external and internal locus of control, autonomy and generalised self-efficacy could indicate that they measure aspects of the same construct (psychological strengths). The relatively low correlation coefficients between locus of control (internal and external) and generalised self-efficacy may indicate that these constructs measure different aspects of behaviour. This finding is contradictory to the expectation that individuals with an external locus of control tend to doubt their personal efficacy (Breed, 1997; Lefcourt, 1982; Rotter, 1966). It should, however, be taken into account that Breed (1997) used Rotter's (1966) scale, which is ipsative in nature, to measure locus of control. Ipsative scales are not suitable for use in correlative studies. Judge $e t$ al. (1998) stated that self-efficacy pertains to confidence with respect to actions or behaviour, whereas locus of control is more concerned with confidence in being able to control outcomes.

The regression formula for the prediction of job satisfaction could be written as follows: Total Job Satisfaction $(\mathrm{MSQ})=1.03(\mathrm{OLQ})-0.78(\mathrm{LOC}$ : External) + 0.64 (LOC: Internal) +0.75 (LOC: Autonomy) +0.68 (GSE) +167.27 . The three psychological strengths predicted 30 per cent of the variance of total job satisfaction in this study. It seems that sense of coherence explains the largest part of the variance in total job satisfaction. However, the moderate correlation 
coefficients between sense of coherence, locus of control and generalised selfefficacy probably limited the multiple correlation (Nunnally \& Bernstein, 1994). The multiple correlation suggests that if employees have a high sense of coherence, a low external locus of control, a high internal locus of control and a high level of autonomy, they will be more satisfied with their jobs.

A limitation of this research is that the research design does not allow one to determine the direction of the relationship between the variables (see Komhauser, 1965). Another limitation is that a non-probability sample has been used, which implies that the findings cannot be generalised to other settings.

\section{RECOMMENDATIONS}

This study generates several application-oriented suggestions. Firstly, organisations can select individuals who have a strong sense of coherence, a low external locus of control and a high level of autonomy, depending on the job. However, before organisations begin selecting employees on the basis of these characteristics, more research is required, especially because these characteristics were not studied in a selection context.

Secondly, organisations can contribute to the development of employees' sense of coherence by giving information in a consistent, structured, ordered and understandable format. Employees should further be able to identify their roles within the greater whole and as such the comprehensibility component of sense of coherence will be enhanced.

Thirdly, by equipping employees with the necessary knowledge, skills, material, instruments and other resources, and by ensuring a balance in the load of tasks to be handled, the employees will increasingly feel that the work expectations are manageable and within their or important other's power. Employees should also be given the opportunity to perform work that requires thought and independent judgement. This will also strengthen their task-based self-efficacy. Training and development programmes that are directed at developing psychological strengths (including sense of coherence, locus of control and generalised self-efficacy) should be investigated. Research indicates that dispositional characteristics that relate to coping styles seem to be subject to change (Lachman, 1989).

Fourthly, when a degree of independence and freedom of choice in the performance of employees' tasks is allowed, employees will regard their work as meaningful. Participation in decision-making will enhance the employees' feeling of membership and contribute to the meaningfulness component of sense 
of coherence. Fifthly, the employee should have the freedom to disagree with his or her supervisor, to discuss what to do with his or her supervisor (rather than to be told what to do) and to act autonomously (without being supervised too closely).

The relationship between self-efficacy and job satisfaction should be investigated in other contexts and with larger samples. Other instruments, which measure generalised self-efficacy, should also be related to job satisfaction. Alternatively, task-specific self-efficacy, rather than generalised self-efficacy, needs to be researched in organisational settings. Sense of coherence, selfefficacy and locus of control could be investigated in relation to other work outcomes, such as performance and coping with organisational transformation.

\section{REFERENCES}

1 AGHO, A.O; PRICE, J.L. \& MUELLER, C.W. (1992) "Discriminant Validity of Measures of Job Satisfaction, Positive Affectivity and Negative Affectivity", Journal of Occupational and Organizational Psychology, 65, 185-96.

2 ANTONOVSKY, A. (1987) Unravelling the Mystery of Health: How People Manage Stress and Stoy Well, Jossey-Bass, San Francisco, CA.

3 ANTONOVSKY, A. (1991) "The Structural Sources of Salutogenic Strengths", In C.L. Cooper \& R. Payne (eds.), Personality and Stress: Individual Differences in the Stress Process, Wiley, New York.

4 ANTONOVSKY, A. (1993) "The Structure and Properties of the Sense of Coherence Scale", Social Science and Medicine, 36: 725-33.

5 ARVEY, R.D.; CARTER, G.W. \& BUERKLEY, D.K. (1991) "Job satisfaction: Dispositional and Situational Influences", In C.L. Cooper \& I.T. Robertson (eds.), International Review of Industrial and Organizational Psychology, Wiley, Chichester.

6 BANDURA, A. (1982) "Self-Efficacy Mechanism in Human Agency", American Psychologist, 37: 122-47.

7 BANDURA, A. (1989) "Human Agency in Social Cognitive Theory", American Psychologist, 44: 1175-84.

8 BASSETT, G. (1994) "The Case Against Job Satisfaction" Business Horizons, 9: 61-68.

9 BEN-SIRA, Z. (1985) "Potency: A Stress-Buffering Link in the CopingStress-Disease Relationship", Social Science and Medicine, 21: 397-406.

10 BOTHMA, A.C. \& SCHEPERS, J.M. (1997) "The Role of Locus of Control and Achievement Motivation in the Work Performance of Black Managers", Journal of Industrial Psychology, 23(3): 44-52. 
11 BREED, M. (1997) Bepalende Persoonlikheidstrekke in die Salutogenetiese Paradigma, Unpublished doctoral thesis, University of South Africa, Pretoria.

12 CARMEL, S. \& BERNSTEIN, J. (1989) "Trait-Anxiety and Sense of Coherence: A Longitudinal Study", Psychological Reports, 65: 221-2.

13 CLARK, L.A. \& WATSON, D. (1995) "Constructing Validity: Basic issues in Objective Scale Development", Psychological Assessment, 7: 309-19.

14 COHEN, J. (1988) Statistical Power Analysis for the Behavioral Sciences (rev. ed.), Academic Press, Orlando.

15 COOK, J.D.; HEPWORTH, S.J.; WALL, T.D. \& WARR, P.B. (1981) The Experience of Work: A Compendium and Review of 249 Measures and Their Use, Academic Press, London.

16 CRANNY, C.J.; SMITH, P.C., \& STONE, E.F. (1992) Job Satisfaction: How People Feel About Their Jobs and How It Affects Their Performance, Macmillan, New York.

17 DAVIS-BLAKE, A., \& PFEFFER, J. (1989) "Just a Mirage: The Search for Dispositional Effects in Organisational Research", Academy of Management Review, 14: 385-400.

18 DAWIS, R.V. (1992) "Person-Environment Fit and Job Satisfaction", In C.J. Cranny; P.C. Smith \& E.F. Stone (eds.), Job Satisfaction: How People Feel about Their Jobs and How It Affects Their Performance (pp. 69-88), Macmillan, New York.

19 EDEN, D. (1988) "Pygmalion, Goal Setting, and Expectancy: Compatible Ways to Boost Productivity", Academy of Management Review, 13: 63952.

20 EDEN, D. \& ZUK, Y. (1995) "Seasickness as a Self-fulfilling Prophecy: Raising Self-Efficacy to Boost Performance at Sea", Journal of Applied Psychology, 80: 628-35.

21 FELDT, T. (1997) "The Role of Sense of Coherence in Well-being at Work: Analysis of Main and Moderator Effects", Work and Stress, 11: 134-47.

22 FLANNERY, R.B. \& FLANNERY, G.J. (1990) "Sense of Coherence, Life Stress, and Psychological Distress: A Prospective Methodological Enquiry", Journal of Clinical Psychology, 46: 415-20.

23 FRENZ, A.W.; CAREY, M.P. \& JORGENSEN, R.S. (1993) "Psychometric Evaluation of Antonovsky's Sense of Coherence Scale", Psychological Assessment, 5: 145-53.

24 GARDNER, D.G. \& PIERCE, J.L. (1998) "Self-esteem and Self-efficacy Within the Organisational Context: An Empirical Examination", Group and Organisation Management, 23: 48-70. 
25 GARSON, E.G. \& STANWYCK, D.J. (1997) "Locus of Control and Incentive in Self-managing Teams", Human Resource Development Quarterly, 8(3): 17-23.

26 HOUSE, R.J.; SHANE, S.A. \& HEROLD, D.M. (1996) "Rumours of the Death of Dispositional Research are Vastly Exaggerated", Academy of Management Review, 21: 203-24.

27 IAFFALDANO, M.T. \& MUCHINSKY, P.M. (1985) "Job Satisfaction and Job Performance: A Meta-analysis", Psychological Bulletin, 97: 25173.

28 JAIN, V.K; MCLAUGHLIN, D.G.; LALL, R. \& JOHNSON, W.B. (1996) "Effects of Locus of Control, Occupational Stress and Psychological Distress on Job Satisfaction among Nurses", Psychological Reports, 78: 1256-58.

29 JUDGE, T.A., LOCKE, E.A., DURHAM, C.C. \& KLUGER, A.N. (1998) "Dispositional Effects on Job and Life Satisfaction: The Role of Core Evaluations", Journal of Applied Psychology, 83: 17-34.

30 KALIMO, R \& VUORI, J. (1990) "Work and Sense of Coherence: Resources for Competence and Life Satisfaction", Behavioural Medicine, 16: 76-89.

31 KOBASA, S.C. (1982) "The Hardy Personality: Towards a Social Psychology of Stress and Health", In G.S. Sanders \& J. Suls (Eds.), Social Psychology of Health and Ilness: 3-32, Erlbaum, Hillsdale, NJ.

32 KORNHAUSER, A. (1965) "Mental Health of the Industrial Worker", Wiley, New York.

33 LACHMAN, M.E. (1989) "Personality and Aging at the Crossroads: Beyond Stability Versus Change”, In K.W. Schaie \& C. Schooler (eds.), Social Structure and Aging: Psychological Processes, Erlbaum, Hillsdale, NJ.

34 LEE, C. \& BOBKO, P. (1994) "Self-Efficacy Beliefs: Comparison of Five Measures", Journal of Applied Psychology, 79: 364-9.

35 LEFCOURT, H. (1982) "Locus of Control: Current Trends in Theory and Research", Wiley, New York.

36 MAKIN, P.J.; COOPER, C.L. \& COX, C.J. (1996) “Organizations and the Psychological Contract: Managing People at Work", British Psychological Society, Leicester.

37 MARAIS, C.P. (1997) "Salutogenesis as Paradigm in Change Management", Unpublished master's dissertation, University of South Africa, Pretoria.

38 MAYER, F.S. \& SUTTON, K. (1996) Personality: An Integrative Approach, Prentice-Hall, Upper Saddle River, NJ.

39 MLONZI, E.N. \& STRÜMPFER, D.J.W. (1998) "Antonovsky's Sense of Coherence Scale and 16PF Second-order Factors", Social Behaviour and Personality, 26: 39-50. 
40 NUNNALLY, J.C. \& BERNSTEN, I.H. (1994) Psychometric Theory (3 ${ }^{\text {rd }}$ ed.), McGraw-Hill, New York.

41 ORGAN, D.W. \& KONOVSKY, M. (1989) “Cognitive Versus Affective Determinants of Organisational Citizenship Behaviour", Journal of Applied Psychology, 74: 157-164.

42 RAHIM, M.A. \& PSENICKA, C. (1996) “A Structural Equation Model of Stress, Locus of Control, Social Support, Psychiatric Symptoms and Propensity to Leave a Job", Journal of Social Psychology, 136: 69-84.

43 ROBERTS, H.E. \& ROSEANNE, F.J. (1998) "Evaluating the Interaction between Self-leadership and Work Structure in Predicting Job Satisfaction", Journal of Business and Psychology, 12: 257-67.

44 ROSENBAUM, M. (1988) "Learned Resourcefulness, Stress and SelfRegulation", In S. Fisher, \& J. Reason (eds.), Handbook of Life-stress, Cognition and Health (pp. 483-96), Wiley, Chichester.

45 ROTTER, J.B. (1966) "Generalised Expectancies for Internal Versus External Control of Reinforcement", Psychological Monographs, 80: 128.

46 ROZNOVSKI, M. \& HULIN, C. (1992) “The Scientific Merit of Valid Measures of General Constructs with Special Reference to Job Satisfaction and Job Withdrawal", In C.J. Cranny, P.J Smith \& E.F. Stone (Eds.), Job Satisfaction: How People Feel About Their Jobs and How It Affects Their Performance, Lexington Books, New York.

47 SADRI, G. \& ROBERTSON, I.T. (1993) "Self-efficacy and Work-related Behavior: A Review and Meta-analysis", Applied Psychology: An International Review, 42: 139-52.

48 SAS INSTITUTE. (1996) "SAS Users Guide: Basics", (6" ed.), SAS Institute, Cary, NC.

49 SCHEPERS, J.M. (1995) Die Lokus van Beheer Vraelys: Konstruksie en Evaluering van ' $n$ Meetinstrument, Randse Afrikaanse Universiteit, Johannesburg.

50 SCHWOERER, C.E. \& MAY, D.R. (1996) “Age and Work Outcomes: The Moderating Effects of Self-efficacy and Tool Design Effectiveness", Journal of Organisational Behaviour, 17: 469-87.

51 SEEMAN, M. \& SEEMAN, T.E. (1983) "Health Behaviour and Personal Autonomy: A Longitudinal Study of the Sense of Control in Illness", Journal of Health and Social Behaviour, 24: 144-60.

52 SHAUGHNESSY, J.J. \& ZECHMEISTER, E.B. (1997) Research Methods in Psychology, (4 ${ }^{\text {th }}$ ed.), McGraw-Hill, New York.

53 SHELTON, S.H. (1990) "Developing the Construct of General SelfEfficacy", Psychological Reports, 66: 987-94.

54 Sherer, M., Maddux, J.E., Mercadante, B., Prentice-Dunn, S., Jacobs, B. \& Rogers, R.W. (1982) "The Self-efficacy Scale: Construction and Validation", Psychological Reports, 51: 663-71. 
55 SNEDECOR, G.W. \& COCHRAN, W.G. (1980) Statistical Methods, (7 ed.), Iowa State University Press, Ames, IA.

56 SPECTOR, P.E. (1982) "Behavior in Organizations as a Function of Employees' Locus of Control", Psychological Bulletin, 91: 482-97.

57 SPECTOR, P.E. (1986) "Perceived Control by Employees: A MetaAnalysis of Studies Concerning Autonomy and Participation at Work", Human Relations, 39: 1005-16.

58 STANLEY, K.D. \& MURPHY, M.R. (1997) "A Comparison of General Self-Efficacy with Self-Esteem", Genetic, Social, and General Psychology Monographs, 123: 79-99.

59 STAW, B.M., BELL, N.E. \& CLAUSEN, J.A. (1986) "The Dispositional Approach to Job Attitudes: A Lifetime Longitudinal Test", Administrative Science Quarterly, 31: 56-77.

60 STEEL, R.P. \& RENTSCH, J.R. (1995) "Influence of Cumulative Strategies on the Long-Range Prediction of Absenteeism", Academy of Management Journal, 38: 616-1634.

61 STEYN, H.S. (1999) "Praktiese Betekenisvolheid: Die Gebruik van Effekgroottes", Wetenskaplike bydraes - Reeks B: Natuurwetenskappe Nr. 117, PU vir CHO, Potchefstroom.

62 STRÜMPFER, D.J.W. (1990) "Salutogenesis: A New Paradigm", South African Journal of Psychology, 20: 265-76.

63 STRÜMPFER, D.J.W. (1995) "The Origins of Health and Strength: From 'Salutogenesis' to 'Fortigenesis', South African Journal of Psychology, 25: 81-9.

64 STRÜMPFER, D.J.W.; DANANA, N.; GOUWS, J.F. \& VIVIERS, M.R. (1998) "Personality Dispositions and Job Satisfaction", South African Journal of Psychology, 28: 92-100.

65 TIPTON, R.M. \& WORTHINGTON, E.L. (1984) "The Measurement of Generalized Self-efficacy: A Study of Construct Validity", Journal of Personality Assessment, 48: 545-8.

66 WEISS, D.J.; DAWIS, R.V.; ENGLAND, G.W. \& LOFQUIST, L.H. (1967) Manual for the Minnesota Satisfaction Questionnaire, University of Minnesota, Minneapolis, MN.

67 WEISS, H.M. \& CROPANZANO, R. (1996) "Affective Events Theory: A Theoretical Discussion of the Structure, Causes, and Consequences of Affective Experiences at Work, Research in Organizational Behaviour, 18: 1-74.

68 WOOD, R.E. \& BANDURA, A. (1989) "Impact of Conceptions of Ability on Self-regulatory Mechanisms and Complex Decision-making", Journal of Personality and Social Psychology, 56: 407-15. 